\title{
Variations of deep soil moisture under different vegetation types and influencing factors in a watershed of the Loess Plateau, China
}

\author{
Xuening Fang ${ }^{1}$, Wenwu Zhao ${ }^{1,2}$, Lixin Wang ${ }^{2}$, Qiang Feng ${ }^{1,3}$, Jingyi Ding ${ }^{1}$, Yuanxin Liu ${ }^{1}$, and Xiao Zhang ${ }^{1}$ \\ ${ }^{1}$ State Key Laboratory of Earth Surface Processes and Resource Ecology, College of Resource and Technology, \\ Beijing Normal University, Beijing 100875, P. R. China \\ ${ }^{2}$ Department of Earth Sciences, Indiana University-Purdue University Indianapolis (IUPUI), \\ Indianapolis, Indiana 46202, USA \\ ${ }^{3}$ College of Forestry, Shanxi Agricultural University, Taigu, Shanxi 030801, P. R. China \\ Correspondence to: Wenwu Zhao (zhaoww@bnu.edu.cn) and Lixin Wang (lxwang@iupui.edu)
}

Received: 14 January 2016 - Published in Hydrol. Earth Syst. Sci. Discuss.: 19 January 2016

Revised: 26 June 2016 - Accepted: 15 July 2016 - Published: 12 August 2016

\begin{abstract}
Soil moisture in deep soil layers is a relatively stable water resource for vegetation growth in the semi-arid Loess Plateau of China. Characterizing the variations in deep soil moisture and its influencing factors at a moderate watershed scale is important to ensure the sustainability of vegetation restoration efforts. In this study, we focus on analyzing the variations and factors that influence the deep soil moisture (DSM) in $80-500 \mathrm{~cm}$ soil layers based on a soil moisture survey of the Ansai watershed in Yan'an in Shanxi Province. Our results can be divided into four main findings. (1) At the watershed scale, higher variations in the DSM occurred at $120-140$ and $480-500 \mathrm{~cm}$ in the vertical direction. At the comparable depths, the variation in the DSM under native vegetation was much lower than that in human-managed vegetation and introduced vegetation. (2) The DSM in native vegetation and human-managed vegetation was significantly higher than that in introduced vegetation, and different degrees of soil desiccation occurred under all the introduced vegetation types. Caragana korshinskii and black locust caused the most serious desiccation. (3) Taking the DSM conditions of native vegetation as a reference, the DSM in this watershed could be divided into three layers: (i) a rainfall transpiration layer $(80-220 \mathrm{~cm})$; (ii) a transition layer (220 $400 \mathrm{~cm}$ ); and (iii) a stable layer $(400-500 \mathrm{~cm})$. (4) The factors influencing DSM at the watershed scale varied with vegetation types. The main local controls of the DSM variations were the soil particle composition and mean annual rainfall; human agricultural management measures can alter the soil bulk density, which contributes to higher DSM in farmland
\end{abstract}

and apple orchards. The plant growth conditions, planting density, and litter water holding capacity of introduced vegetation showed significant relationships with the DSM. The results of this study are of practical significance for vegetation restoration strategies, especially for the choice of vegetation types, planting zones, and proper human management measures.

\section{Introduction}

Soil moisture is an indispensable component of terrestrial systems and plays a critical role in surface hydrological processes, especially runoff generation, soil evaporation and plant transpiration (Cheema et al., 2011; Legates et al., 2011; Wang et al., 2012a; Zhao et al., 2013). Soil moisture in different soil layers is usually related to different hydrological processes and ecological functions (Yang et al., 2012a). Surface or shallow layer soil moisture is usually greatly influenced by rainfall infiltration or evapotranspiration and is a regular water source for vegetation growth, while the moisture in deep soil layers functions as a soil reservoir. During the years with heavy rainfall, deep soil moisture (DSM) can be replenished by rainfall infiltration; during drought years, DSM can provide necessary water for plant growth and is thus important for plant growth during dry seasons (Yang et al., 2012c; Jia and Shao, 2014). This relationship is particularly true in semi-arid areas, such as the Loess Plateau of China, where water resources are incredibly scarce. In such 
regions, DSM even becomes the main constraining factor of plant productivity and ecosystem sustainability (Wang et al., 2010c, 2011a). Traditionally the boundary of deep soil moisture is not clearly defined. In this study, we define the deep soil layer as the layer whose soil moisture is not sensitive to daily evapotranspiration and regular rainfall events.

The Loess Plateau of China is located in a semi-arid area. The average annual rainfall in this region ranges from 150 to $800 \mathrm{~mm}$, which is far lower than the average annual pan evaporation (1400-2000 mm; Wang et al., 2010b). Low precipitation and high evaporation results in lower soil moisture content in this region. The shallow soil moisture is not sufficient to meet the growth needs of introduced vegetation (Yang et al., 2014b). Moreover, the thickness of loess soil in this area ranges from 30 to $80 \mathrm{~m}$; at these depths, groundwater is not available for plants (Wang et al., 2013). Therefore, DSM that is stored in unsaturated soil becomes an important water resource for plant growth (Yang et al., 2012c). However, the vegetation that has been introduced by the national Grain for Green project tends to have strong water consumption. Large-scale afforestation has resulted in the excessive consumption of DSM, and a large range of soil desiccation has been reported (Wang et al., 2008b, 2010b, c, 2011b). Soil desiccation greatly reduces the capability of a "soil reservoir" to supply water to deep soil layers for plant growth in the Loess Plateau (Chen et al., 2008a). Introduced vegetation in desiccated land is easily degraded with low productivity, and "dwarf aged trees" with heights of 3-5 m have widely appeared. Therefore, the sustainability of the restored ecosystem is being challenged. Moreover, traditional soil moisture studies, which have mainly focused on shallow soil layers (Gómez-Plaza et al., 2000; Bi et al., 2009; Baroni et al., 2013), cannot clearly reveal the sustainability needs for vegetation restoration.

In recent years, several studies have been conducted on the variations in DSM and factors influencing DSM in the Loess Plateau (Liu et al., 2010; Wang et al., 2012b, 2013; Yang et al., 2014a; Jia and Shao, 2014; Sun et al., 2014). Deep soil moisture is an indispensable water source for vegetation growth in the semi-arid Loess Plateau; understanding the variations and influencing factors of DSM is important for "timely, suitable, and moderate" vegetation restoration and can also help in developing proper measures to control soil desiccation. In fact, DSM is a result of long-term biophysical processes that are controlled by multiple factors (Vereecken et al., 2007). Several factors may impact DSM variations, such as vegetation traits, soil properties, topographical factors, climate factors, and human landscape management measures (Qiu et al., 2001; Lu et al., 2007, 2008; Vivoni et al., 2008; Zhu and Lin, 2011; Montenegro and Ragab, 2012). The dominant factors that affect DSM variations depend on the research scale (Entin et al., 2000). For instance, DSM variations are mainly dominated by the type of vegetation at the slope scale $\left(0.1-1 \mathrm{~km}^{2}\right.$; Jia et al., 2013). Additionally, vegetation and topography are key fac- tors that contribute to DSM variations at the small catchment scale (1-100 km²; Yang et al., 2012a). Meanwhile, Wang et al. (2012b) reported that DSM variations at the regional scale (i.e., the Loess Plateau, covering $640000 \mathrm{~km}^{2}$ ) are mainly determined by plant types and climatic conditions. Vegetation factors play an important role in spatial variations of DSM at all scales (Western et al., 2004).

While all spatial scales, from slopes and small catchments to regions, are relevant to understanding DSM variations, some scales are more operational and meaningful than others. For example, slope- and small catchment-based studies tend to be too small in spatial extent to incorporate all environmental factors and human-managed measures because soil traits, climate characteristics, and human-managed measures are usually homogeneous at one slope or small catchment (Gómez-Plaza et al., 2000; Bi et al., 2009; Zhu et al., $2014 a, b)$. At the same time, it is often impossible to assess the mechanistic details of DSM variations to guide local policies at the regional scale since high variations in rainfall and temperature can cover the influencing effects of other factors (Wang et al., 2010a, d, 2012c). A moderate scale that covers an area of approximately $100-1000 \mathrm{~km}^{2}$ over a watershed or a geopolitically defined area represents a pivotal scale domain for research on DSM variation mechanisms. In particular, people and nature interact most acutely at this scale (Zhao and Fang, 2014; Fang et al., 2015), which is a more operational scale for sustainable vegetation restoration policy making. To date, however, minimal research on DSM variations has centered on such a moderate scale, and the variation mechanisms of DSM at this scale are still unclear.

In this study, we aim to reveal the variations in DSM and its influencing factors at a moderate watershed scale. This study includes shallow root vegetation and deep root vegetation, covering eight specific vegetation types. We first identify the deep soil layer in the Ansai watershed, whose soil moisture is not sensitive to regular rainfall and daily evapotranspiration. Then, we explore the overall variation in DSM in this area, compare the DSM of various vegetation types with different root systems, and identify variations in their profiles. Finally, the influence of various environmental factors on the DSM under different vegetation types is discussed. The objectives of this study are to (1) quantify the variation characteristics of DSM, (2) explore the mechanisms for controlling DSM variability among different vegetation types at the watershed scale, and (3) develop recommendations for land use management and the sustainability of vegetation recovery for the Loess Plateau.

\section{Materials and methods}

\subsection{Study area}

The Yanhe watershed lies in the middle of the Loess Plateau in northern Shaanxi Province. The Ansai watershed 


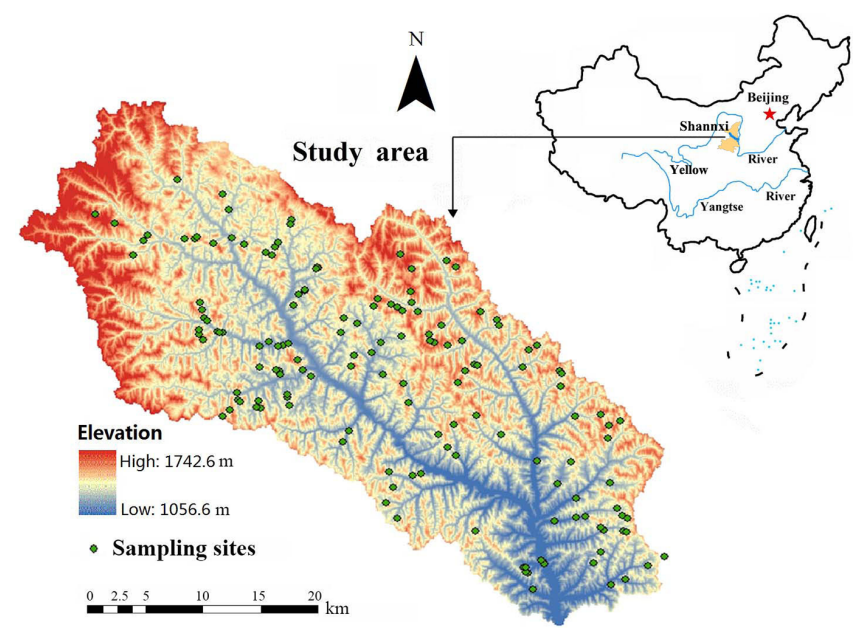

Figure 1. Location of the study area and sampling sites.

$\left(108^{\circ} 47^{\prime}-109^{\circ} 25^{\prime} \mathrm{E}, 36^{\circ} 52^{\prime}-37^{\circ} 19^{\prime} \mathrm{N}\right.$; Fig. 1) is located in the upstream section of the Yanhe river and covers an area of approximately $1334 \mathrm{~km}^{2}$. This watershed has a highly fragmented terrain, and the elevation here ranges from 1057 to $1743 \mathrm{~m}$ above sea level. This typical semi-arid loess hilly region has a mean annual temperature of $8.8^{\circ} \mathrm{C}$, and the average annual precipitation ranges from 375 to $546 \mathrm{~mm}$ across the watershed (Fig. S1 in the Supplement). Most rainfall occurs in the form of thunderstorms during the summer months from June to September. The soil types in this study area include loess soil with low fertility and vulnerability to soil erosion (Zhao et al., 2012). The soil texture is different across the watershed, with the sand content ranging from 24 to $57 \%$, the silt content ranging from 40 to $65 \%$, and the clay content ranging from 6 to $10 \%$ (Fig. S2).

The predominant land use types in the Ansai watershed are rain-fed farmland, orchard land, sparse native grassland, pasture grassland, shrubland, and forest (Feng et al., 2013). The native vegetation in the study area consists of sparse grasses with shallow roots that are dominated by species such as bunge needlegrass, common leymus, and Altai heteropappus (Heteropappus altaicus (Willd.) Novopokr). Non-native species, such as alfalfa, black locust, David peach, sea buckthorn, and Caragana korshinskii, were predominantly used in the study area under the national Grain for Green project. The cultivated crops are predominantly maize, millet and broom corn millet. Because this region is located in a semi-arid climatic zone, water resources represent the major constraint of vegetation growth and agricultural crop production.

\subsection{Sampling locations and description}

Two vegetation groups with different root systems were selected: (1) shallow root vegetation, including native grasses (NGs) and farmland (FL) with human agricultural measures; and (2) deep root vegetation, including pasture grasses
(PGs), sea buckthorn (SB), Caragana korshinskii (CK), David peach (DP), black locust (BL) and apple orchard (AO) with human agricultural measures. Descriptions of the root distribution of the selected vegetation types are provided in Table 1.

To fully explore the influencing factors of deep soil moisture, we examined topographic factors, surface soil properties, vegetation traits, and climate factors. These factors further included 23 independent variables: average annual rainfall (AAR), altitude (Al), slope position (SP), slope aspect (SA), slope gradient (SG), clay $(\mathrm{Cl})$, silt $(\mathrm{Sl})$, sand $(\mathrm{Sa})$, organic matter $(\mathrm{OM})$, capillary porosity $(\mathrm{CP})$, soil bulk density (SBD), vegetation coverage (VC), grass biomass (GB), grass height $(\mathrm{GH})$, planting density $(\mathrm{PD})$, plant height $(\mathrm{PH})$, diameter at breast height (DBH), crown width (CW), basal diameter (BD), litter maximum water holding (LMWH), litter biomass (LB), and clear bole height (CBH). The distance between each vegetation sampling site was at least $2 \mathrm{~km}$. The sampling locations are shown in Fig. 1. The main characteristics and sampling numbers for each vegetation type are shown in Table 2.

\subsection{Data collection and analysis}

Soil samples were collected from depths of 0-500 $\mathrm{cm}$ using a soil drill $(5 \mathrm{~cm}$ in diameter) with $20 \mathrm{~cm}$ increments within 28 days (from 10 July to 6 August 2014). The soil samples were sealed and taken to the laboratory, and the gravimetric soil moisture content was determined via oven drying at $105^{\circ} \mathrm{C}$ to a constant weight. Three sampling profiles were randomly chosen to obtain the average soil moisture content for each sampling site. Native grasses and Caragana korshinskii were selected as representatives of shallow root vegetation and deep root vegetation, respectively. Soil moisture dynamic data $(0-200 \mathrm{~cm})$ of these vegetation types were monitored by EM50 $\left(109^{\circ} 19^{\prime} 23 \mathrm{E}, 36^{\circ} 51^{\prime} 26 \mathrm{~N}\right)$ from the same time period in 2015. The average annual rainfall (2006-2013) was provided by 29 rain gauges in or around the Ansai watershed, and the inverse distance weighted (IDW) interpolation method was performed in ArcGIS10.0 to obtain the average annual rainfall at each sampling site (Fig. S1).

The longitude, latitude and altitude were collected for each experimental site by using a Garmin GPS (version eTrex 30). The slope gradients and slope aspects were determined by using the compass method in field investigations; the slope gradients were transformed into tan (slope), and the slope aspects (clockwise from north) were transformed into cos (aspect). At each sampling site, six undisturbed soil cores were collected from the soil surface in metal cylinders (diameter of $5 \mathrm{~cm}$, length of $5 \mathrm{~cm}$ ) to measure the bulk density and capillary porosity (Wang et al., 2008a). The bulk density was determined from the volume-mass relationship for each core sample, and the capillary porosity was measured by the "cylinder soak method". Soil samples were also collected at each sampling site. The soil particle size distri- 
Table 1. Descriptions of the root distributions of the selected vegetation species.

\begin{tabular}{lll}
\hline Vegetation type & Root distribution traits & Source \\
\hline NG & $\begin{array}{l}\text { The roots of native grasses are usually } \\
\text { distributed at depths of } 0-50 \mathrm{~cm} .\end{array}$ & Han et al. (2009) \\
\hline PG & $\begin{array}{l}\text { The fibrous roots of pasture grasses are mainly distributed at } \\
\text { depths of 0-50 cm, while taproot systems can extend to 3 m. }\end{array}$ & $\begin{array}{l}\text { Wei et al. (2006); } \\
\text { Wang et al. (2010d) }\end{array}$ \\
\hline FL & The roots of farmland are mainly distributed at depths of 0-40 cm. & Feng et al. (2007) \\
\hline AO & $\begin{array}{l}\text { Ninety percent of apple tree roots are distributed at } \\
\text { depths of 0-120 cm, while deep roots can reach } 160 \mathrm{~cm} .\end{array}$ & Lei (2013) \\
\hline CK & $\begin{array}{l}\text { The fibrous roots of Caragana korshinskii are mainly distributed } \\
\text { at depths of 0-100 cm, while taproot systems can extend to 6.4 m. }\end{array}$ & Wang et al. (2010d) \\
\hline SB & $\begin{array}{l}\text { The fibrous roots of sea buckthorn are mainly distributed at } \\
\text { soil depths of 0-160 cm, while deep roots can reach 200-300 cm. }\end{array}$ & Chong and Liang (1990) \\
\hline DP & $\begin{array}{l}\text { Ninety percent of David peach roots are distributed within } \\
\text { depths of } 100 \mathrm{~cm}, \text { while deep roots can reach } 150 \mathrm{~cm} .\end{array}$ & Shi et al. (1989) \\
\hline BL & $\begin{array}{l}\text { Coarse roots are mainly distributed within depths } \\
\text { of } 260 \mathrm{~cm}, \text { while fine roots can reach } 350 \mathrm{~cm} .\end{array}$ & Zhang and Xu (2011) \\
\hline
\end{tabular}

Table 2. Main characteristics and sampling numbers for different vegetation types.

\begin{tabular}{|c|c|c|c|c|c|c|c|c|}
\hline \multirow[t]{2}{*}{ Vegetation conditions } & \multicolumn{3}{|c|}{ Shallow root vegetation } & \multicolumn{5}{|c|}{ Deep root vegetation } \\
\hline & $\mathrm{NG}^{*}$ & FL & $\mathrm{AO}$ & PG & $\mathrm{CK}$ & SB & DP & $\mathrm{BL}$ \\
\hline Sampling number & 25 & 22 & 10 & 11 & 18 & 15 & 12 & 38 \\
\hline Altitude (m) & 1392.6 & 1380.1 & 1370.1 & 1401.0 & 1350.6 & 1435.7 & 1377.6 & 1326.5 \\
\hline Slope aspect $\left({ }^{\circ}\right)$ & 170.7 & 200.6 & 173.5 & 195.4 & 161.8 & 195.8 & 128.1 & 156.4 \\
\hline Slope gradient $\left({ }^{\circ}\right)$ & 16.7 & 6.3 & 19.9 & 13.1 & 17.6 & 16.4 & 24.2 & 27.2 \\
\hline Sand $(\%)$ & 44.9 & 39.4 & 38.2 & 55.3 & 46.4 & 46.2 & 52.7 & 40.0 \\
\hline Silt (\%) & 47.1 & 52.6 & 53.6 & 38.2 & 46.6 & 46.9 & 47.3 & 51.8 \\
\hline Clay $(\%)$ & 8.1 & 7.9 & 8.2 & 6.5 & 7.0 & 7.0 & 7.4 & 8.3 \\
\hline Organic matter $\left(\mathrm{g} \mathrm{kg}^{-1}\right)$ & 7.0 & 5.3 & 5.8 & 6.3 & 13.3 & 8.9 & 6.0 & 8.1 \\
\hline Soil bulk density $\left(\mathrm{g} \mathrm{cm}^{-3}\right)$ & 1.3 & 1.3 & 1.3 & 1.3 & 1.3 & 1.2 & 1.3 & 1.2 \\
\hline Capillary porosity $(\%)$ & 48 & 46 & 48 & 47 & 49 & 48 & 49 & 49 \\
\hline Mean canopy coverage (\%) & 57.4 & 53.3 & 39.7 & 67.8 & 45.6 & 66.1 & 33.8 & 59.6 \\
\hline Mean canopy height (m) & 0.6 & 1.8 & 3.6 & 0.7 & 1.7 & 1.9 & 3.0 & 11.8 \\
\hline Mean tree DBH $(\mathrm{cm})$ & - & - & 6.3 & - & - & - & 5.0 & 10.4 \\
\hline Mean crown $(\mathrm{cm})$ & - & - & 398.4 & - & 199.7 & 184.9 & 293.4 & 455.3 \\
\hline Basal diameter $(\mathrm{cm})$ & - & - & 10.2 & - & 1.3 & 3.8 & 8.1 & 12.9 \\
\hline Planting density $\left(\mathrm{m}^{2}\right)$ & - & - & 30.5 & - & 129.7 & 262.4 & 36.2 & 58.7 \\
\hline
\end{tabular}

* NG, FL, AO, PG, CK, SB, DP and BL refer to native grasses, farmland, apple orchard, pasture grasses, Caragana korshinskii, sea buckthorn, David peach and black locust, respectively.

butions were measured by using a laser scattering particle size distribution analyzer (BT-9300H, Dandong, China). The proportions of clay $(<0.002 \mathrm{~mm})$, silt $(0.002-0.02 \mathrm{~mm})$, and sand $(>0.02 \mathrm{~mm})$ content were then calculated. The soil organic matter content was determined by using the dichromate oxidation method ( $\mathrm{Hu}$ et al., 2010). A vegetation investigation was also conducted at each sampling site. The stand density (plants ha $\left.{ }^{-1}\right)$, tree height $(\mathrm{m})$, diameter at breast height $(\mathrm{DHB}, \mathrm{cm})$, basal diameter $(\mathrm{cm})$, under branch height $(\mathrm{m})$, canopy width in a $20 \mathrm{~m} \times 20 \mathrm{~m}$ quadrat, and total canopy or coverage of each quadrat were recorded at the forest sites. The stand density (plants ha ${ }^{-1}$ ), plant height $(\mathrm{m})$, basal diameter $(\mathrm{cm})$, and canopy width in a $10 \mathrm{~m} \times 10 \mathrm{~m}$ quadrat were measured at the shrub sites. The species composition, total herbaceous coverage, grass height $(\mathrm{m})$, litter and grass biomass were measured in each herbaceous quadrat. The canopy cover was measured by visual estimation, and the lit- 

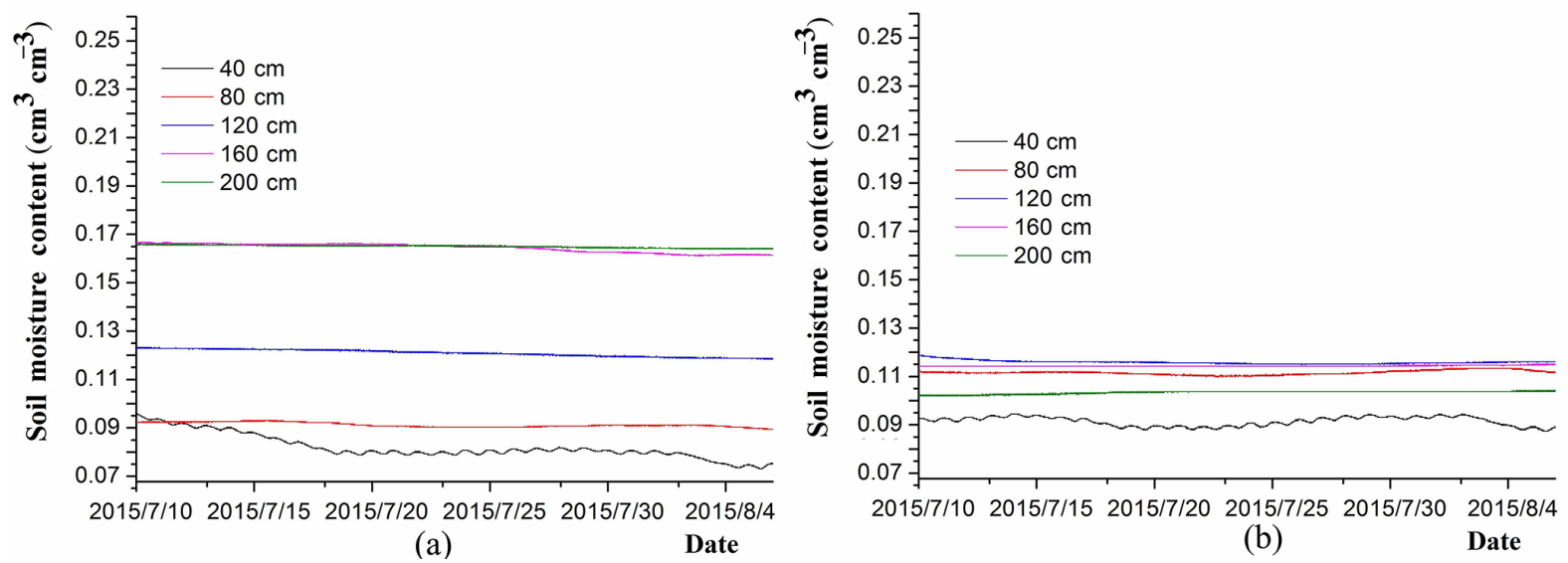

Figure 2. Soil moisture $(0-200 \mathrm{~cm})$ dynamics during the sampling period: (a) native grasses with a shallow root system and (b) Caragana korshinskii with a deep root system.

ter maximum water holdup was measured by using the immersion method.

\subsection{Statistical analyses}

The DSM from each layer was pooled together for the 151 sampling locations to conduct a descriptive analysis. Basic population statistics, such as minimum values (Min), maximum values (Max), mean values (Mean), standard deviations (SD), and coefficients of variation (CV), were reported for both the overall soil moisture datasets and for each vegetation type. The SD and CV values were employed to reflect the degree of variability of the DSM in different layers and for different vegetation types (Ruan and Li, 2002). Oneway ANOVA was used to assess the contribution of different vegetation cover types to the overall variation in the DSM. Multiple comparisons were made by using the least significant difference (LSD) method. First, Spearman correlation analysis was used to examine the relationships between the DSM and environmental variables to determine the factors contributing to the DSM dynamics. Then, principle component analysis was performed to reduce the linear correlation that may exist among selected environmental variables and to further identify a minimum data set (MDS) of environmental variables for each vegetation type. All the statistical analyses were performed by using SPSS (Version 20.0).

\section{Results}

\subsection{Deep soil moisture identification}

The soil moisture dynamics at $0-200 \mathrm{~cm}$ during the sampling period are reported in Fig. 2. The soil moisture under both deep and shallow root vegetation types fluctuated daily at a depth of $40 \mathrm{~cm}$, while the soil moisture at $80-200 \mathrm{~cm}$ remained constant with time. Thus, the evapotranspiration during the sampling period influences the soil moisture no deeper than $80 \mathrm{~cm}$ under both shallow and deep root vegetation types. According to both Figs. 2 and S3, the soil moisture at $40 \mathrm{~cm}$ did not change obviously with rainfall events, which indicates that rainfall during the monitoring period influenced the soil moisture no deeper than $40 \mathrm{~cm}$.

According to Fig. S3, the mean air temperature and rainfall of the monitoring period in 2015 were similar to those observed during the sampling time period in 2014; thus, rainfall and evapotranspiration during the sampling time period influenced the soil moisture no deeper than $80 \mathrm{~cm}$. In this study, we consider soil moisture at depths of $80-500 \mathrm{~cm}$ as deep soil moisture.

\subsection{Summary statistics of deep soil moisture}

The summary statistics of the DSM at various depths are listed in Table 3. In general, the mean soil moisture, SD, and CV highly depended on the depth. The profile distributions of the mean DSM, SD, and CV are listed in Table 3 and Fig. 3. The highest mean value $(9.45 \%)$ was observed at depths of $400-500 \mathrm{~cm}$, the lowest $(8.15 \%)$ was observed at depths of $120-140 \mathrm{~cm}$, and the mean DSM below $300 \mathrm{~cm}$ was almost constant. However, both the SD and CV showed varying trends with increasing depth (Fig. 3). The profile distributions of the SD and CV were consistent. The highest values of both parameters occurred at 100-120 and $480-500 \mathrm{~cm}$ (Table 3), which indicated that the DSM at these depth ranges had relatively higher variability. Meanwhile, the lowest values occurred at $260-300 \mathrm{~cm}$, which indicated lower variability of DSM at these depth ranges. Most of the kurtosis (except for $80-120 \mathrm{~cm}$ ) and skewness values were positive, and the highest values of both factors occurred at depths of $200-240 \mathrm{~cm}$. The Kolmogorov-Smirnov test indicated that the soil moisture data sets were normally distributed. Thus, statistical analysis could be performed without data transformation 

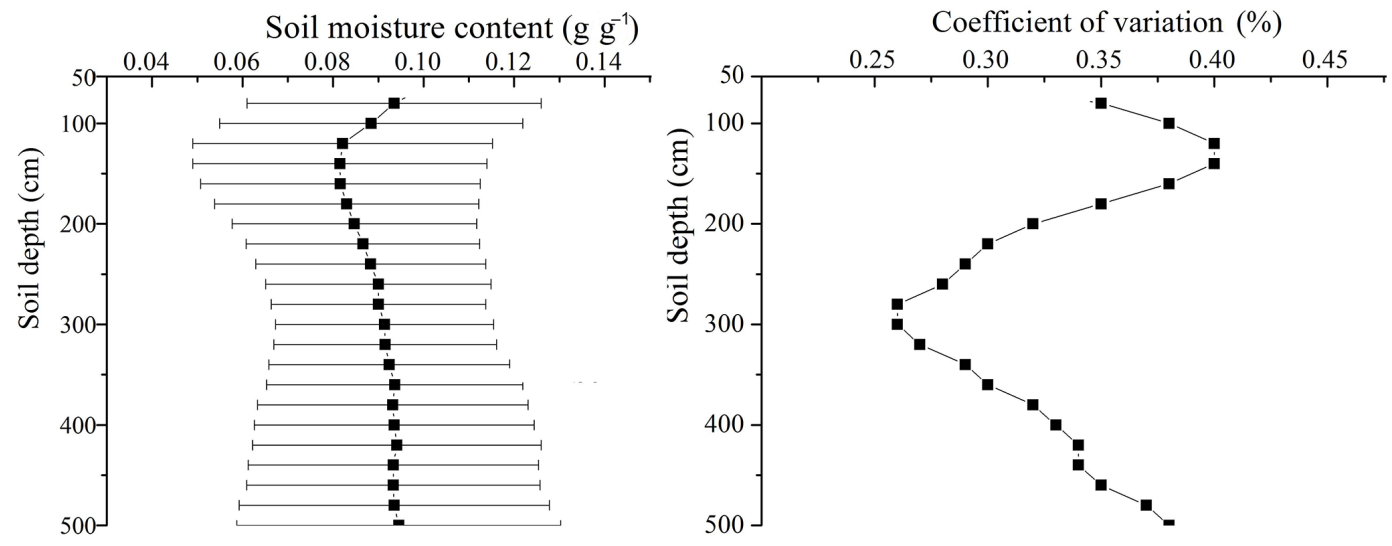

Figure 3. Profile distribution of the deep soil moisture contents and coefficients of variation. The error bars indicate the standard deviation.

Table 3. Summary statistics of the deep soil moisture at various depths in the Ansai watershed.

\begin{tabular}{lrrrrrrrrr}
\hline $\begin{array}{l}\text { Depth } \\
(\mathrm{cm})\end{array}$ & $n^{\mathrm{a}}$ & $\begin{array}{r}\text { Mean } \\
(\%)\end{array}$ & $\begin{array}{r}\mathrm{SD}^{\mathrm{b}} \\
(\%)\end{array}$ & $\begin{array}{r}\text { Minimum } \\
(\%)\end{array}$ & $\begin{array}{r}\text { Maximum } \\
(\%)\end{array}$ & $\mathrm{CV}^{\mathrm{c}}$ & $\mathrm{K}^{\mathrm{d}}$ & $\mathrm{S}$ & $\mathrm{K}-\mathrm{S}$ \\
\hline $80-100$ & 151 & 8.84 & 3.35 & 2.60 & 18.29 & 0.38 & -0.45 & 0.28 & $N(0.95)$ \\
$100-120$ & 151 & 8.21 & 3.31 & 3.29 & 18.23 & 0.40 & -0.27 & 0.57 & $N(1.36)$ \\
$120-140$ & 151 & 8.15 & 3.25 & 3.22 & 18.95 & 0.40 & 0.30 & 0.75 & $N(0.93)$ \\
$140-160$ & 151 & 8.16 & 3.09 & 3.37 & 18.56 & 0.38 & 0.40 & 0.80 & $N(0.99)$ \\
$160-180$ & 151 & 8.30 & 2.92 & 3.14 & 17.85 & 0.35 & 0.70 & 0.85 & $N(1.06)$ \\
$180-200$ & 151 & 8.47 & 2.70 & 3.22 & 17.89 & 0.32 & 1.48 & 1.01 & $N(1.13)$ \\
$200-220$ & 151 & 8.66 & 2.58 & 3.47 & 19.19 & 0.30 & 2.35 & 1.06 & $N(1.23)$ \\
$220-240$ & 151 & 8.83 & 2.54 & 3.59 & 19.72 & 0.29 & 2.99 & 1.05 & $N(1.02)$ \\
$240-260$ & 151 & 9.00 & 2.49 & 3.92 & 19.47 & 0.28 & 2.33 & 0.88 & $N(0.94)$ \\
$260-280$ & 151 & 9.00 & 2.37 & 4.08 & 18.46 & 0.26 & 1.94 & 0.74 & $N(1.11)$ \\
$280-300$ & 151 & 9.14 & 2.41 & 3.56 & 18.72 & 0.26 & 1.35 & 0.53 & $N(0.65)$ \\
$300-320$ & 151 & 9.15 & 2.46 & 3.26 & 18.08 & 0.27 & 1.45 & 0.54 & $N(0.73)$ \\
$320-340$ & 151 & 9.24 & 2.66 & 3.09 & 19.56 & 0.29 & 1.92 & 0.67 & $N(0.81)$ \\
$340-360$ & 151 & 9.36 & 2.83 & 2.98 & 19.38 & 0.30 & 1.31 & 0.59 & $N(0.91)$ \\
$360-380$ & 151 & 9.32 & 2.99 & 3.13 & 19.88 & 0.32 & 1.49 & 0.61 & $N(0.91)$ \\
$380-400$ & 151 & 9.35 & 3.09 & 2.81 & 20.85 & 0.33 & 1.99 & 0.60 & $N(1.00)$ \\
$400-420$ & 151 & 9.41 & 3.19 & 2.68 & 21.92 & 0.34 & 2.09 & 0.60 & $N(0.80)$ \\
$420-440$ & 151 & 9.33 & 3.21 & 2.70 & 20.97 & 0.34 & 1.43 & 0.55 & $N(0.57)$ \\
$440-460$ & 151 & 9.33 & 3.24 & 2.65 & 19.63 & 0.35 & 0.20 & 0.23 & $N(0.73)$ \\
$460-480$ & 151 & 9.35 & 3.43 & 2.67 & 19.88 & 0.37 & -0.08 & 0.26 & $N(0.84)$ \\
$480-500$ & 151 & 9.45 & 3.58 & 2.43 & 19.98 & 0.38 & -0.22 & 0.23 & $N(0.87)$ \\
\hline
\end{tabular}

${ }^{\mathrm{a}} n$ refers to the number of sampling points. ${ }^{\mathrm{b}} \mathrm{SD}$ refers to the standard deviation. ${ }^{\mathrm{c}} \mathrm{CV}$ refers to the coefficient of variation. ${ }^{\mathrm{d}} \mathrm{K}$, $\mathrm{S}$, and $\mathrm{K}-\mathrm{S}$ refer to the kurtosis, skewness, and Kolmogorov-Smirnov test values, respectively. $N$ refers to the normal distribution (significance level is 0.05 , Kolmogorov-Smirnov value is in parentheses).

Moreover, different vegetation types greatly determined the variation in the DSM; the DSM statistics of various vegetation types under different vegetation types are reported in Fig. 4. The results showed that the depth-averaged DSM of native grasses and human-managed vegetation (farmland and apple orchard) were significantly higher than that of introduced deep root vegetation. In general, the mean DSM of different vegetation covers could be organized as follows: $\mathrm{FL}>\mathrm{NG}>\mathrm{AO}>\mathrm{DP}>\mathrm{SB}>\mathrm{PG}>\mathrm{BL}>\mathrm{CK}$. The highest $\mathrm{DSM}$ existed in farmland and the lowest in Caragana korshinskii.
This result indicated that human agricultural management measures can significantly improve DSM conditions and that Caragana korshinskii showed the greatest water consumption among the selected introduced vegetation types.

\subsection{Profile distribution of deep soil moisture by vegetation type}

According to a previous study, the soil moisture profile characteristics in vegetation covering zones are usually complex 


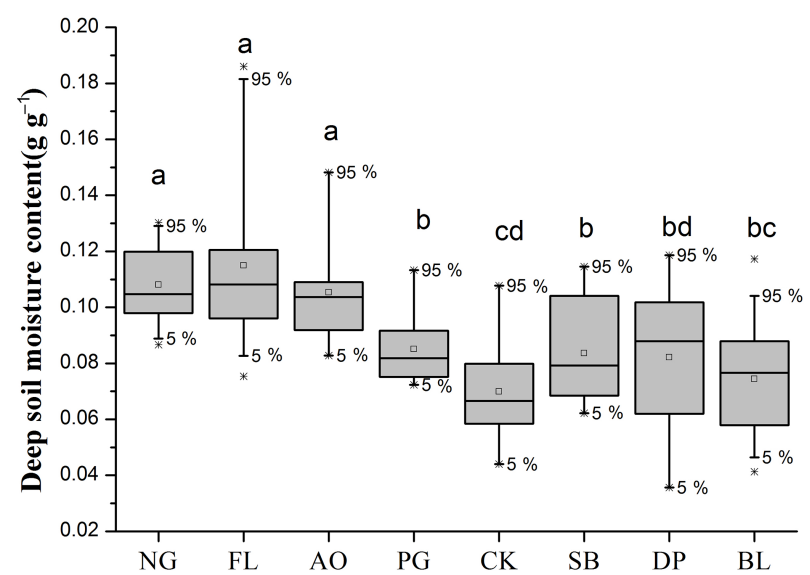

Figure 4. Deep soil moisture statistics for different vegetation types. Means with the same letter above the box are not significantly different at the 0.05 significance level (LSD test); NG, FL, AO, PG, $\mathrm{CK}, \mathrm{SB}, \mathrm{DP}$ and BL refer to native grasses, farmland, apple orchard, pasture grasses, Caragana korshinskii, sea buckthorn, David peach and black locust, respectively.

(Jia et al., 2013). Thus, soil moisture profiles for each vegetation type were chosen for analysis. As expected, the profile distribution characteristics of the DSM varied with the vegetation type (Fig. 5).

The DSM in native grassland zones is seldom affected by vegetation because of shallow root systems; thus, the DSM in native grasslands can be regarded as a reference (Yang et al., $2012 \mathrm{c})$. The $80-500 \mathrm{~cm}$ soil moisture profile of native grasslands can be divided into three layers based on the inflection point of the DSM and the changes in the SD:

1. $80-220 \mathrm{~cm}$; in this layer, both the DSM and SD decreased as the soil depth increased, which indicates that this layer may be a main rainfall infiltration layer. Furthermore, the level of rainfall infiltration decreased as the depth increased;

2. $220-400 \mathrm{~cm}$; the DSM in this layer remained relatively constant as the soil depth increased, but its SD increased with soil depth, which indicates that this layer is unstable. We characterize this layer as a transition layer;

3. $400-500 \mathrm{~cm}$; this section is a relatively stable layer whose SD is constant as the soil depth increases, despite the increasing DSM with soil depth. In this layer, the DSM is seldom influenced by rainfall infiltration. The profile distribution characteristics of farmland and apple orchards were similar to those of native grasslands, except for the $300-500 \mathrm{~cm}$ layer, possibly because management measures increased the ranges of the rainfall infiltration layer.

The DSM of all the introduced vegetation types reached a minimum at depths of $80-220 \mathrm{~cm}$. The DSM of different introduced vegetation at $220-500 \mathrm{~cm}$ could be generally divided into three categories: (1) the DSM increased as the soil depth increased (e.g., PG and SB), (2) the DSM remained relatively stable as the soil depth increased (e.g., DP and BL), and (3) the DSM increased first before decreasing as the soil depth increased (e.g., CK).

We generally divided the DSM in this watershed into three layers based on the above analysis: (i) a rainfall transpiration layer $(80-220 \mathrm{~cm})$, which is a main rainfall infiltration layer and can be greatly influenced by vegetation transpiration; (ii) a transition layer $(220-400 \mathrm{~cm})$, which can be recharged by rainfall infiltration during heavy rainfall years and can supply deep root vegetation with DSM during drought years; and (iii) a stable layer $(400-500 \mathrm{~cm})$, which has a DSM that is seldom influenced by rainfall infiltration during regular years but can be influenced by extremely deep root vegetation such as $\mathrm{CK}$ and BL.

The profile variation of DSM under different vegetation types displayed different characteristics as well (Fig. S4). The vertical variation of native grassland was clearly less than that in human-managed farmland, orchard and introduced vegetation, and the variation was relatively stable as depth increased. In human-managed vegetation (farmland and orchard), the variation was relatively higher and had a complex profile distribution due to different management measures. However, the variation in introduced vegetation was, to some extent, consistent with the overall variation characteristics in this area (Fig. 3), which indicates that introduced vegetation plays an important role in the vertical variation of DSM in this area.

\subsection{Comparison of deep soil moisture contents under different vegetation types}

Generally, the DSM at comparable soil depths was lower in introduced deep root vegetation (pasture grassland, shrubland and forestland) compared to native grassland and human-managed vegetation (farmland and orchard). Farmland (11.07-11.79\%) had the highest DSM, followed by native grasses (10.52-11.19\%). The LSD test indicated that the DSM in native grasses and farmland was significantly higher than that in introduced vegetation $(P<0.05$, Table 4$)$ at almost every soil depth. The DSM varied from 6.81 to $10.4 \%$ in pasture grassland, 6.85-9.75\% in sea buckthorn, 6.10 $8.07 \%$ in Caragana korshinskii, 7.19-7.66\% in black locust, and $7.71-8.51 \%$ in David peach at depths of $80-500 \mathrm{~cm}$. The LSD test indicated significant differences in the DSM at depths of $400-500 \mathrm{~cm}$ between different introduced vegetation types. For example, Caragana korshinskii was significantly different from pasture grassland, sea buckthorn, and David peach, while black locust was significantly different from pasture grassland and sea buckthorn $(P<0.05$, Table 4$)$.

As shown in Fig. 6, the DSM in farmland was higher than that in native grassland, and soil desiccation occurred in all the introduced vegetation. However, soil desiccation varied 


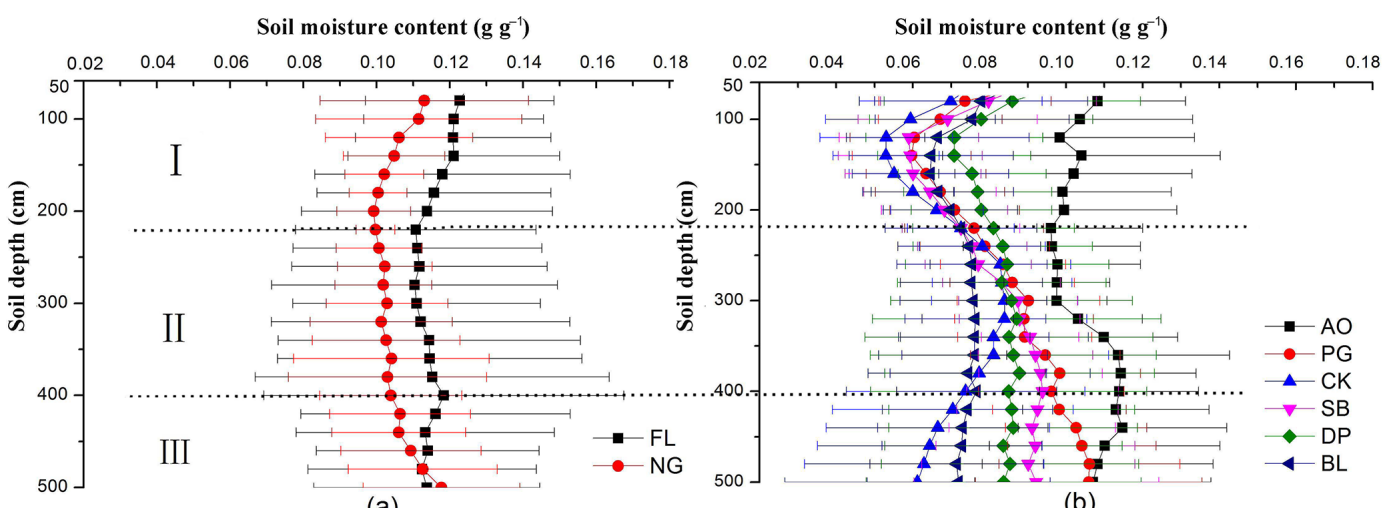

Figure 5. Profile distribution of DSM for different vegetation types: (a) shallow root system vegetation (NG - native grass; FL - farmland) and (b) deep root system vegetation (PG - pasture grasses; CK - Caragana korshinskii; SB - sea buckthorn; DP - David peach; BL - black locust; AO - apple orchard). The error bars indicate the standard deviation. I-III: DSM at different soil layer depth ranges (I: 80-220 cm, II: $220-400 \mathrm{~cm}$, and III: $400-500 \mathrm{~cm}$ ). The dashed lines are the boundaries of different soil layer depth ranges.

Table 4. Deep soil moisture of the $80-500 \mathrm{~cm}$ soil layers for different vegetation types.

\begin{tabular}{|c|c|c|c|c|c|c|c|c|c|c|c|c|c|}
\hline \multirow{2}{*}{$\begin{array}{l}\text { Root } \\
\text { types }\end{array}$} & \multirow{2}{*}{$\begin{array}{l}\text { Vegetation } \\
\text { types }\end{array}$} & \multicolumn{4}{|c|}{$80-220 \mathrm{~cm}$} & \multicolumn{4}{|c|}{$220-400 \mathrm{~cm}$} & \multicolumn{4}{|c|}{$400-500 \mathrm{~cm}$} \\
\hline & & $\operatorname{Min} \%$ & $\operatorname{Max} \%$ & Mean $\%$ & SD \% & $\operatorname{Min} \%$ & Max \% & Mean \% & SD \% & $\operatorname{Min} \%$ & Max \% & Mean \% & SD \% \\
\hline \multirow{2}{*}{$\begin{array}{l}\text { Shallow root } \\
\text { vegetation }\end{array}$} & $\mathrm{NG}^{*}$ & 8.4 & 13.8 & $10.9 \mathrm{a}$ & 1.5 & 8.4 & 12.8 & $10.5 \mathrm{ab}$ & 1.6 & 8.2 & 14.7 & $11.2 \mathrm{ab}$ & 2.0 \\
\hline & FL & 7.3 & 17.9 & $11.8 \mathrm{a}$ & 2.8 & 7.8 & 18.6 & $11.1 \mathrm{a}$ & 3.2 & 7.5 & 20.0 & $11.8 \mathrm{a}$ & 3.6 \\
\hline Deep root & $\mathrm{AO}$ & 6.9 & 15.4 & 10.1ab & 2.7 & 7.7 & 14.1 & $10.5 \mathrm{abc}$ & 1.7 & 7.4 & 15.3 & $11.4 \mathrm{ab}$ & 2.3 \\
\hline \multirow[t]{5}{*}{ vegetation } & PG & 4.8 & 8.9 & $6.8 \mathrm{c}$ & 1.3 & 7.7 & 13.1 & $9.0 \mathrm{bcd}$ & 1.6 & 8.5 & 14.3 & $10.4 a b c$ & 1.9 \\
\hline & SB & 4.9 & 11.3 & $6.9 \mathrm{c}$ & 1.8 & 7.1 & 12.1 & $8.9 \mathrm{~cd}$ & 1.6 & 5.1 & 14.7 & $9.8 \mathrm{bc}$ & 2.6 \\
\hline & CK & 4.2 & 8.8 & $6.1 \mathrm{c}$ & 1.4 & 4.9 & 11.6 & $8.1 \mathrm{~d}$ & 2.1 & 2.6 & 12.5 & $6.5 \mathrm{e}$ & 2.9 \\
\hline & BL & 3.8 & 12.8 & $7.2 \mathrm{c}$ & 2.1 & 4.2 & 10.9 & $7.7 \mathrm{~d}$ & 1.8 & 4.0 & 13.3 & $7.5 \mathrm{de}$ & 2.5 \\
\hline & DP & 3.7 & 10.7 & $7.7 \mathrm{bc}$ & 2.1 & 3.8 & 14.0 & $8.5 \mathrm{~d}$ & 3.2 & 3.2 & 13.1 & $8.5 \mathrm{~cd}$ & 3.2 \\
\hline
\end{tabular}

letter in the same column are not significantly different at the 0.05 significance level (LSD).

among the vegetation types. In general, the DSM in layer I $(80-220 \mathrm{~cm})$ was heavily consumed in almost all the introduced vegetation types. PG and SB consumed less DSM in layers II-III $(220-500 \mathrm{~cm})$ compared to the three other introduced vegetation types, while the DSM in layers II-III $(220-500 \mathrm{~cm})$ of DP and BL was consumed more consistently. Double-layer soil desiccation occurred in CK, which indicates that the DSM in layers I and III of CK was heavily consumed, while the DSM in layer II was less consumed. Despite the deep root system of the apple orchards, soil desiccation did not occur across the soil profile from 80 to $500 \mathrm{~cm}$; even in the $320-450 \mathrm{~cm}$ layer, the DSM in the apple orchards was higher than that in native grasses.

\subsection{Spearman correlation coefficients between deep soil moisture and selected environmental variables}

Although the DSM data were normally distributed, significant correlations existed between the soil moisture contents at different soil depth ranges. Thus, non-parametric correlation tests (Spearman) were used to determine the strength of possible relationships between the DSM and selected vari- ables. The correlation analysis results are presented in Tables S1, S2, and S3 in the Supplement. The correlation between the DSM and environmental variations changed with the soil depth and vegetation type. The DSM in native grassland showed significant correlations with the altitude $(80$ $500 \mathrm{~cm}$ ), slope gradient $(220-500 \mathrm{~cm})$, soil particle composition $(80-500 \mathrm{~cm})$, and average annual rainfall $(220-400 \mathrm{~cm})$. The DSM in farmland $(80-220 \mathrm{~cm})$ was only influenced by the bulk density. The DSM in areas of introduced vegetation, apart from the significant correlations with the topography, soil properties, and average annual rainfall, showed different correlations with vegetation growth traits. For instance, the DSM of BL showed significant negative correlations with the plant height $(80-220 \mathrm{~cm})$ and diameter at breast height $(400-500 \mathrm{~cm})$, and the DSM of SB showed a significant negative correlation with the plant density $(80-500 \mathrm{~cm})$. A significant correlation was found between the aspect and DSM in some introduced vegetation in PG $(400-500 \mathrm{~cm})$ and BL $(80-400 \mathrm{~cm})$. Moreover, positive correlations existed between the DSM and soil surface conditions; for instance, the DSM of DP showed significant correlations with the grass biomass $(400-500 \mathrm{~cm})$, the DSM of AO showed significant 


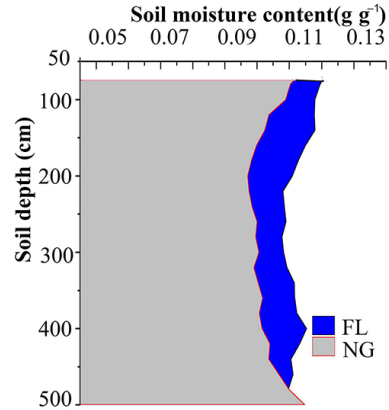

(a)

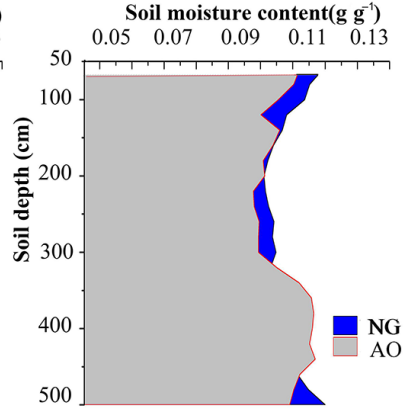

(b)

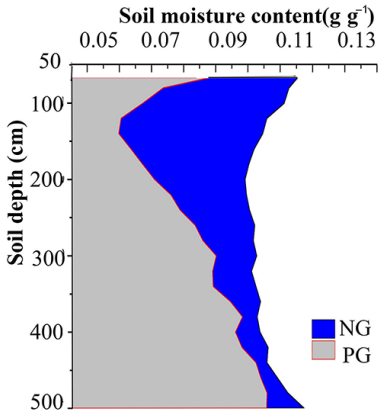

(c)

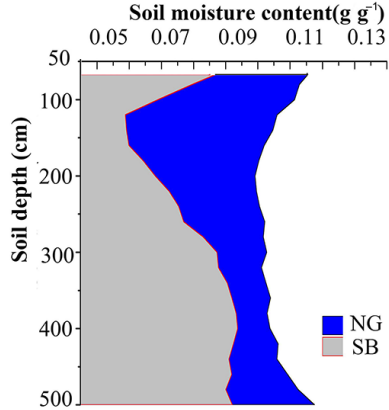

(d)

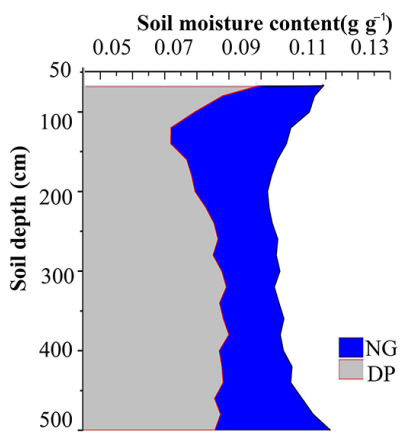

(e)

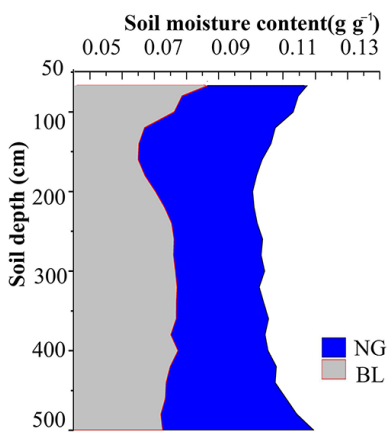

(f)

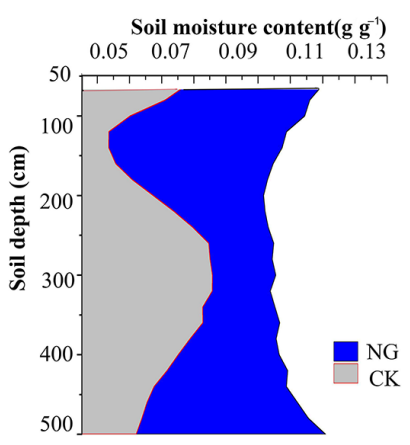

(g)

Figure 6. Comparison of deep soil moisture among human-managed vegetation, introduced vegetation and native grasslands: (a) farmland (FL) and native grasses (NG), (b) apple orchard (AO) and native grasses (NG), (c) pasture grasslands (PG) and native grasses (NG), (d) sea buckthorn (SB) and native grasses (NG), (e) David peach (DP) and native grasses (NG), (f) black locust (BL) and native grasses (NG), (g) Caragana korshinskii (CK) and native grasses (NG).

correlations with the litter biomass $(400-500 \mathrm{~cm})$, and the DSM of CK showed significant correlations with the litter maximum water holding $(220-500 \mathrm{~cm})$. Furthermore, both the soil bulk density $(80-400 \mathrm{~cm})$ and capillary porosity $(80-$ $220 \mathrm{~cm}$ ) in the apple orchards showed significant correlations with the DSM.

\subsection{Principal component analysis (PCA)}

Only the environmental variables that showed significant correlations $(P<0.05)$ with the DSM were retained for Spearman correlation analysis, including 9 environmental variables for grassland and farmland (Group 1), 7 environmental variables for shrubland (Group 2), and 15 environmental variables for forestland and orchards (Group 3). Some of these variables were linearly correlated, so the dimensionality of these data sets could be reduced. Principal component analysis was performed following $\mathrm{Hu}$ et al. (2010) and $\mathrm{Xu}$ et al. (2008) to obtain an MDS of the environmental variables; the results are listed in Table 5. Only principal components (PCs) with eigenvalues $N>1.0$ and only variables with highly weighted factor loading (i.e., those with absolute values for factor loading within $10 \%$ of the highest value) were retained for the MDS (Mandal et al., 2008; Shi et al., 2014). For Group 1, the PCA identified four PCs that com- prised $80 \%$ of the variance, of which the first three PCs comprised most of this variance $(68 \%)$. For Group 2, four PCs comprised $84 \%$ of the variance. For Group 3, five PCs comprised $75 \%$ of the variance. In grassland and farmland, PC 1 included three variables that had highly weighted factor loadings, including clay, silt, and sand, which indicates that the soil particle composition was the most important factor that influenced variations in the DSM. For PC 2, PC 3, and PC 4, only one variable for each principal component had a high factor loading: the slope aspect, annual average rainfall, and soil bulk density, respectively. In shrubland, the highly weighted factor loadings of PC 1 were silt and sand, while the altitude and plant density were the highly weighted factor loadings for PC 2. For PC 3, only organic matter had a high factor loading. In forestland and orchard land, the diameter at breast height, basal diameter, and sand content comprised the highly weighted factor loadings of PC 1 . The capillary porosity was the only variation that constituted the highly weighted factor loadings of PC 2. Four variations for PC 3 were highly weighted: clay, silt, soil bulk density, and litter maximum water holding. For PC 4 and PC 5, only one variable had a high factor loading: the slope aspect and slope gradient, respectively.

In total, 6 out of 9 environmental variables for grassland and farmland (Group 1), 5 out 7 for shrubs (Group 2), and 
Table 5. Principle component analysis (PCA) of environmental attributes.

\begin{tabular}{|c|c|c|c|c|c|c|c|c|c|c|c|c|}
\hline \multirow[b]{2}{*}{ Principal component } & \multicolumn{4}{|c|}{ Group 1: grassland and farmland } & \multicolumn{3}{|c|}{ Group 2: shrubland } & \multicolumn{5}{|c|}{ Group 3: orchard and forest } \\
\hline & $\mathrm{PC}^{*} 1$ & PC 2 & PC 3 & $\mathrm{PC} 4$ & PC 1 & PC 2 & PC 3 & PC 1 & PC 2 & PC 3 & PC 4 & PC 5 \\
\hline Eigenvalue & 3.6 & 1.5 & 1.1 & 1.1 & 2.2 & 1.9 & 1.0 & 4.5 & 2.6 & 1.8 & 1.2 & 1.1 \\
\hline$\%$ of variance & 39.8 & 16.1 & 12.5 & 11.7 & 31.5 & 26.9 & 14.5 & 30.1 & 17.5 & 12.0 & 7.8 & 7.2 \\
\hline Cumulative $\%$ & 39.8 & 55.8 & 68.3 & 80.0 & 31.5 & 58.9 & 72.9 & 30.1 & 47.6 & 59.5 & 67.3 & 74.5 \\
\hline \multicolumn{13}{|l|}{ Factor loading/eigenvector } \\
\hline Annual average rainfall & 0.21 & -0.50 & 0.71 & 0.06 & -0.39 & -0.59 & -0.39 & & & & & \\
\hline Altitude & -0.46 & 0.23 & 0.53 & 0.51 & 0.24 & 0.83 & 0.05 & & & & & \\
\hline Slope aspect & -0.16 & 0.81 & 0.24 & -0.07 & & & & -0.06 & -0.05 & 0.21 & 0.64 & -0.10 \\
\hline Slope gradient & 0.64 & -0.43 & -0.04 & -0.23 & & & & 0.55 & 0.22 & 0.07 & 0.01 & $-\mathbf{0 . 7 0}$ \\
\hline Clay & 0.86 & 0.25 & -0.13 & 0.15 & & & & 0.64 & -0.44 & -0.50 & -0.03 & -0.04 \\
\hline Silt & 0.93 & 0.27 & 0.05 & 0.09 & -0.94 & 0.16 & 0.27 & 0.68 & -0.44 & -0.45 & 0.28 & 0.08 \\
\hline Sand & -0.94 & -0.27 & -0.02 & -0.11 & 0.95 & -0.16 & -0.24 & -0.77 & 0.39 & 0.37 & -0.23 & -0.17 \\
\hline Organic matter & -0.48 & -0.03 & -0.50 & 0.49 & 0.15 & -0.53 & 0.70 & 0.54 & -0.23 & 0.28 & -0.16 & -0.12 \\
\hline Soil bulk density & -0.41 & 0.31 & 0.07 & -0.67 & & & & -0.25 & 0.61 & -0.49 & 0.29 & -0.05 \\
\hline Capillary porosity & & & & & & & & 0.38 & -0.74 & 0.22 & -0.37 & -0.13 \\
\hline Litter biomass & & & & & & & & 0.54 & 0.43 & -0.29 & -0.04 & 0.20 \\
\hline Litter maximum water holding & & & & & 0.42 & -0.27 & 0.45 & -0.24 & -0.48 & 0.46 & 0.31 & 0.50 \\
\hline Grass biomass & & & & & & & & 0.27 & 0.49 & -0.17 & -0.37 & 0.39 \\
\hline Plant height & & & & & & & & 0.69 & 0.31 & 0.34 & -0.22 & 0.24 \\
\hline Diameter at breast height & & & & & & & & 0.80 & 0.34 & 0.31 & 0.14 & 0.05 \\
\hline Crown width & & & & & & & & 0.39 & 0.20 & 0.43 & 0.22 & -0.09 \\
\hline Basal diameter & & & & & & & & 0.75 & 0.37 & 0.26 & 0.18 & 0.07 \\
\hline Plant density & & & & & 0.10 & 0.77 & 0.22 & & & & & \\
\hline
\end{tabular}

highly weighted when within $10 \%$ of the variation of the absolute values of the highest factor loading in each PC.

10 out of 15 for forests and apple orchards (Group 3) were selected as MDS variables. Moreover, the MDS variables for each vegetation type were selected (Table 6). At the watershed scale, the main influencing factors of variations in the DSM under native grasslands were the soil particle composition (clay, silt, and clay content) and average annual rainfall. In farmland, the dominant influencing factors were the clay content and soil bulk density. The main influencing factors for introduced vegetation types were more complex; apart from the soil texture and physical characteristics, topographical factors and vegetation traits also strongly affected variations in the DSM. Moreover, the main influencing depth ranges of different environmental factors varied with vegetation types. For example, the soil particle size composition in native grasslands and apple orchard land mainly influenced the DSM at $80-220 \mathrm{~cm}$, while the most significant influencing depths in pasture grassland were $220-400 \mathrm{~cm}$. These results indicate that vegetation coverage or human management measures can alter the depths of the environmental factors that influence the DSM.

\section{Discussion}

\subsection{Variation characteristics of deep soil moisture at the watershed scale}

The variations in the DSM at the watershed scale varied with the soil depth (Figs. 3 and 5). At a soil depth of $80-220 \mathrm{~cm}$,
Table 6. Minimum data set of environmental variables.

\begin{tabular}{ll}
\hline Vegetation types & Influencing variables \\
\hline Native grasses & $\mathrm{Cl}^{*}, \mathrm{Sl}, \mathrm{Sa}, \mathrm{AAR}$ \\
Farmland & $\mathrm{Cl}, \mathrm{SBD}$ \\
Apple orchard & $\mathrm{SG}, \mathrm{Cl}, \mathrm{Sl}, \mathrm{Sa}, \mathrm{SBD}, \mathrm{CP}$ \\
Pasture grasses & $\mathrm{SA}, \mathrm{S} 1$ \\
Sea buckthorn & $\mathrm{Al}, \mathrm{S} 1, \mathrm{Sa}, \mathrm{PD}$ \\
Caragana korshinskii & $\mathrm{Al}, \mathrm{S} 1, \mathrm{OM}$ \\
Black locust & $\mathrm{SA}, \mathrm{SG}, \mathrm{DBH}$ \\
David peach & $\mathrm{Cl}, \mathrm{Sa}, \mathrm{BD}, \mathrm{LMWH}$ \\
\hline
\end{tabular}

* Cl, SA, SG, Sl, Sa, OM, CP, SBD, DBH, BD, and LMWH refer to clay, slope aspect, slope gradient, silt, sand, organic matter, capillary porosity, soil bulk density, diameter at breast height, basal diameter, and litter maximum water holding, respectively.

the influence of soil evaporation was relatively weak; rainfall infiltration could be stored in soil without strong consumption from vegetation, and rainfall infiltration decreased as the soil depth increased. Meanwhile, the soil layer at 220 $400 \mathrm{~cm}$ was less influenced by rainfall infiltration; thus, the DSM remained constant as the soil depth increased. Soil depths below $400 \mathrm{~cm}$ comprised a deep stable DSM storage layer (Fig. 5). However, the existence of deep root vegetation and human agricultural management measures altered the vertical DSM distribution rules, resulting in more complex variations (Fig. 3). The highest variations in the DSM at this watershed occurred at $100-120$ and $480-500 \mathrm{~cm}$. However, the DSM was lowest in the $120-140 \mathrm{~cm}$ layer and had 
high variation. This result is inconsistent with previous studies, which reported that high variations usually appear with higher DSM and decrease when the DSM decreases (Ibrahim and Huggins, 2011). This result likely occurred because the most serious soil desiccation occurred in this layer for all the introduced vegetation types (Fig. 6), increasing their difference with native grasses and human management vegetation types and eventually resulting in high variation. While the high variation at $400-500 \mathrm{~cm}$ may have been caused by the different water consuming capacities of different vegetation types, this depth range is rarely influenced by rainfall event infiltration and soil evaporation (Chen et al., 2008b; Wang et al., 2009).

The DSM variation traits also varied with the vegetation types. The DSM variations in native grassland were relatively low and stable. Usually, the roots of native grasses are distributed at depths of $0-50 \mathrm{~cm}$ (Han et al., 2009). Thus, the DSM below this depth is seldom influenced by vegetation transpiration, and local controls, such as topographic factors, soil factors, and climate conditions, may contribute to variations in the DSM. The DSM and its variation in farmland were higher than those in native grassland, which indicates that human agricultural measures can greatly increase DSM and its variation. The DSM for introduced vegetation was significantly lower than that in native grassland, which indicates that soil desiccation occurred for all the introduced vegetation. Moreover, different introduced vegetation showed different soil desiccation traits (Fig. 6). This result is different from that of a previous study (Yang et al., 2012c), which reported that no significant differences existed among different introduced vegetation. This difference was probably caused by differences in the annual precipitation; the mean annual precipitation of Yang's study area was $386 \mathrm{~mm}$, which is far less than that in our study area $(505 \mathrm{~mm})$. This lower annual precipitation resulted in plants not receiving enough water, eventually leading to more homogeneous soil desiccation among the different introduced vegetation. Moreover, the main difference in soil desiccation under introduced vegetation occurred at 80-220 and 400-500 cm (Table 4, Fig. 6), which contributed to the higher variations in DSM in these two layers (Fig. 4).

\subsection{Mechanisms of deep soil moisture variability}

Variations in DSM are the combined result of topographic factors, soil factors, vegetation factors, and climate conditions. In this study, the vegetation type was an important factor that influenced variations in the DSM. The effect of vegetation on the DSM is shown in many aspects. First, different root systems determine different DSM consumption traits for various vegetation types (Fig. 6). Introduced vegetation with a deep root system consumes more and deeper DSM than farmland and native grasses (Table 4). Individual vegetation growth conditions and planting density can also influence variations in the DSM. The individual growth con- ditions in the deeper root systems of forests mainly explain the DSM consumption, while the planting density mainly accounts for the DSM consumption in the shallower root systems of shrubs (Tables S2 and S3). In addition to DSM consumption, canopy interception and surface coverage systems can positively affect the DSM (Martínez-Fernández and Ceballos, 2003; Starks et al., 2006). In this study, the litter biomass, water holding capacity, and forest grasses all showed different degrees of significant positive correlations with the DSM for different vegetation types (Tables S1, S2, and S3), probably because thick litter, humus layers and forest grasses can reduce surface runoff, which may help retain more rainfall for infiltration into deep soil layers. Additionally, these factors can reduce soil evaporation, which may decrease DSM consumption (Vivoni et al., 2008).

Climate factors that affect DSM are mainly determined by differences in rainfall infiltration and solar radiation (Savva et al., 2013). According to previous studies, DSM is relatively stable compared to the shallow layer, especially at depths below $200 \mathrm{~cm}$, and soil moisture in deeper layers is seldom influenced by rainfall events (Wang et al., 2009). However, the DSM in this study $(80-220 \mathrm{~cm}$ in Caragana korshinskii and $220-400 \mathrm{~cm}$ in native grasslands) showed significant positive correlations with the 6-year average annual rainfall, which indicates that DSM may be a long-term result of a water budget surplus.

Topography is another important factor that greatly affects the redistribution and consumption of DSM (Qiu et al., 2001; Zhu et al., 2014b). The slope position, altitude, and slope gradient mainly affect the lateral flow of soil moisture. Lower positions or latitudes usually have higher soil moisture contents (He et al., 2003; Zhu et al., 2014a), while the slope gradient usually shows a negative correlation with the soil moisture content; thus, a steep slope usually has a lower soil moisture content than a gentle slope (Kim et al., 2007). Different slope aspects are usually caused by changes in solar radiation (Yang et al., 2012b; Zhao et al., 2007; Wang et al., 2008a), resulting in different rates of soil moisture evaporation. In this study, the altitude had a negative correlation with the DSM; the slope gradient showed significant positive correlations with the DSM in grasslands $(220-500 \mathrm{~cm})$, while significant negative correlations were found in black locust $(400-500 \mathrm{~cm})$. These results indicate that introduced vegetation can alter the topographic factors' influence on DSM variations. This result was also verified by Yang et al. (2012b), who found that introduced vegetation can lead to homogeneity in the DSM. This relationship was true for the slope aspect, which only showed a positive correlation with the DSM in pasture grasses $(400-500 \mathrm{~cm})$ and black locust $(80-400 \mathrm{~cm})$.

Moreover, different soil traits determine different water transmission and conservancy characteristics, which may greatly influence the flow or storage of water in soil (Western et al., 2004). The DSM in the Loess Plateau is mainly determined by land surface rainfall infiltration and evapotranspira- 
tion. Surface soil properties usually have a greater influence on surface rainfall infiltration and evaporation compared to deep soil properties; thus, we mainly analyzed the influence of surface soil properties on DSM. The result indicated that the soil particle composition was an important factor influencing variations in DSM at the watershed scale. Both the clay and silt content showed significantly positive correlations with the DSM, and the sand content showed a negative correlation with the DSM for most vegetation types. However, the soil bulk density and capillary porosity only showed significant correlations with the DSM in farmland $(80-220 \mathrm{~cm})$ and apple orchards $(80-400 \mathrm{~cm})$. This result indicates that human agricultural management measures or other factors that result in lower soil bulk density and higher capillary porosity conditions can significantly improve the infiltration capacity and thus increase the DSM.

\subsection{Implications for land use management and vegetation recovery}

A balance between soil water availability and water utilization by plants is crucial to maintaining ecosystem health, particularly in the arid and semi-arid regions of the Loess Plateau. The implementation of the "Grain for Green" program has effectively controlled soil erosion (Chen et al., 2010; Wang et al., 2015). However, according to this study, soil desiccation occurred in almost all the introduced vegetation, while higher soil moisture contents were found in native grassland and farmland (Fig. 6). These phenomena indicate that the improper selection of vegetation type is a dominant reason for soil desiccation in this area. Thus, more attention should be paid to the selection of vegetation types based on the interactions between soil moisture and vegetation. Among these selected vegetation types, $\mathrm{CK}$ and BL caused the most serious soil desiccation (Figs. 4 and 6); thus, these two types are especially unsuitable for large-scale plants in the study area, while SB, PG, and DP can be properly planted under good soil moisture conditions with suitable planting density and human management measures.

Furthermore, proper planting locations should also be considered based on DSM conditions. Annual average rainfall spatial variations can significantly influence DSM conditions (Tables S1 and S2). Thus, the annual average rainfall is another important factor for determining planting locations. Vegetation enclosure and natural restoration may be good choices in lower rainfall zones, while shrubs and forests could be rationally arranged in higher rainfall zones. DSM was not evenly distributed even within the same rainfall regions: lower altitudes (such as a gully bottom or lower slope) usually had higher DSM (Tables S1 and S2), while the DSM of native grasslands along steeper slopes was higher than that along gentle slopes (Table S1). Thus, shrubs or trees with high water consumption capacities can be arranged at these locations. Native grass and low-moisture-consuming shrubs can be arranged at higher altitudes or upper slopes, where the DSM is lower.

The results of this study also indicate that human agricultural management measures can effectively improve DSM conditions. The DSM of farmland was the highest among the selected vegetation types (Fig. 4); even though introduced vegetation has deep root systems, no soil desiccation was found in apple orchards (Fig. 6). Most of the farmlands that we surveyed were level terraces and back-slope level benches with cultivation practices, while apple orchards were equipped with artificial rainwater gathering measures. All these agricultural measures can significantly increase rainwater infiltration, eventually resulting in higher DSM in these vegetation zones. Moreover, forest grasses, litter biomass, and litter maximum water holding showed significant correlations with the DSM in this study (Tables S2 and S3). Thus, increasing the land surface cover (such as crop straw coverage and mix-sowing shrubs and grass) can be another effective measure to improve DSM recharge. Likewise, vegetation control (when artificial forests and shrubs are mature, the density should be reduced according to deep soil water conditions) may be an effective measure to reduce soil desiccation because the plant density has a significantly negative correlation with the DSM.

\section{Conclusions}

At watershed scale, the variations in the DSM changed with the soil depth and vegetation types. Higher variations in DSM occurred at two depth ranges, namely, 120-140 and 480$500 \mathrm{~cm}$, while variations in native grasses in the horizontal direction were far lower than those of farmland, apple orchards, and introduced vegetation at comparable depths. Soil desiccation occurred for almost all the vegetation types; among them, CK and BL were the most serious. Moreover, $80-220 \mathrm{~cm}$ soil depth had the most serious desiccation layer. The high DSM in farmland and apple orchards indicated that human management measures could greatly improve DSM. Although the vegetation type was a dominant factor, the variations in the DSM in this area were actually the combined result of the climate, vegetation, topography, soil, and human management measures. The DSM in native grassland was found to be significantly related to the topography, soil traits and annual average rainfall. The plant growth conditions, planting density, and litter water holding capacity showed significant relationships with the DSM for introduced vegetation. Human management measures greatly increased the influence of soil traits on the DSM in farmland and orchards, which increased rainfall infiltration and improved the DSM. Proper selection of the vegetation type, planting locations, and landscape management measures can be suggested based on the results of this study. The results of this study are of practical significance for vegetation restoration strategies and the sustainability of restored ecosystems. 


\section{Data availability}

All the data used in this study are available on request.

\section{The Supplement related to this article is available online at doi:10.5194/hess-20-3309-2016-supplement.}

Acknowledgements. This work was supported by the National Natural Science Foundation of China (no. 41390462) and the Program for Changjiang Scholars and Innovative Research Team in University (no. IRT_15R06). Lixin Wang acknowledges support from USDA grant 2014-51130-22492. Wenwu Zhao acknowledges the support from China Scholarship Council (no. 201406045031). We are also grateful to the Ansai Research Station of Soil and Water Conservation, Chinese Academy of Sciences, for their support and contributions to this fieldwork. We are thankful for reviews from the editor, N. Ursino, and five anonymous reviewers, which significantly improved the quality of this article.

Edited by: N. Ursino

Reviewed by: five anonymous referees

\section{References}

Baroni, G., Ortuani, B., Facchi, A., and Gandolfi, C.: The role of vegetation and soil properties on the spatio-temporal variability of the surface soil moisture in a maize-cropped field, J. Hydrol., 489, 148-159, 2013.

Bi, H., Li, X., Liu, X., Guo, M., and Li, J.: A case study of spatial heterogeneity of soil moisture in the Loess Plateau, western China: A geostatistical approach, Int. J. Sediment Res., 24, 6373, 2009.

Cheema, M. J. M., Bastiaanssen, W. G. M., and Rutten, M. M.: Validation of surface soil moisture from AMSR-E using auxiliary spatial data in the transboundary Indus basin, J. Hydrol., 405, 137-149, 2011.

Chen, H., Shao, M., and Li, Y.: Soil desiccation in the Loess Plateau of China, Geoderma, 143, 91-100, 2008a.

Chen, H., Shao, M., and Li, Y.: The characteristics of soil water cycle and water balance on steep grassland under natural and simulated rainfall conditions in the Loess Plateau of China, J. Hydrol., 360, 242-251, 2008b.

Chen, L., Wang, J., Wei, W., Fu, B., and Wu, D.: Effects of landscape restoration on soil water storage and water use in the Loess Plateau region, China, Forest Ecol. Manag., 259, 1291-1298, 2010.

Chong, X. and Liang, Y.: Root distribution characteristics and soil moisture dynamics of Hippophae rhamnoides in semiarid region of Loess Plateau, B. Soil Water Conserv., 98-103, 1990 (in Chinese).

Entin, J. K., Robock, A., Vinnikov, K. Y., Hollinger, S. E., Liu, S., and Namkhai, A.: Temporal and spatial scales of observed soil moisture variations in the extratropics, J. Geophys. Res.-Atmos., $105,11865-11877,2000$
Fang, X., Zhao, W., Fu, B., and Ding, J.: Landscape service capability, landscape service flow and landscape service demand: a new framework for landscape services and its use for landscape sustainability assessment, Prog. Phys. Geogr., 39, 817-836, 2015.

Feng, D., Zongsuo, L., Xuexuan, X., Lun, S., and Xingchang, Z.: Community biomass of abandoned farmland and its effects on soil nutrition in the Loess hilly region of Northern Shaanxi, China, Acta Ecol. Sin., 27, 1673-1683, 2007 (in Chinese).

Feng, Q., Zhao, W., Qiu, Y., Zhao, M., and Zhong, L.: Spatial heterogeneity of Soil moisture and the scale variability of its influencing factors: a Case Study in the Loess Plateau of China, Water, 5, 1226-1242, 2013.

Gómez-Plaza, A., Alvarez-Rogel, J., Albaladejo, J., and Castillo, V. M.: Spatial patterns and temporal stability of soil moisture across a range of scales in a semi-arid environment, Hydrol. Process., 14, 1261-1277, 2000.

Gómez-Plaza, A., Martınez-Mena, M., Albaladejo, J., and Castillo, V. M.: Factors regulating spatial distribution of soil water content in small semiarid catchments, J. Hydrol., 253, 211-226, 2001.

Han, F., Zheng, J., and Zhang, X.: Plant root system distribution and its effect on soil nutrient on slope land converted from farmland in the Loess Plateau, Transactions of the Chinese Society of Agricultural Engineering, 25, 50-55, 2009.

He, F., Huang, M., and Dang, T.: Distribution characteristic of dried soil layer in Wangdonggou watershed in gully region of the Loess Plateau, J. Nat. Resour., 18, 30-36, 2003.

Hu, W., Shao, M., Han, F., Reichardt, K., and Tan, J.: Watershed scale temporal stability of soil water content, Geoderma, 158, 181-198, 2010.

Ibrahim, H. M. and Huggins, D. R.: Spatio-temporal patterns of soil water storage under dryland agriculture at the watershed scale, J. Hydrol., 404, 186-197, 2011.

Jia, Y. and Shao, M.: Dynamics of deep soil moisture in response to vegetational restoration on the Loess Plateau of China, J. Hydrol., 519, 523-531, 2014.

Jia, Y., Shao, M., and Jia, X.: Spatial pattern of soil moisture and its temporal stability within profiles on a loessial slope in northwestern China, J. Hydrol., 495, 150-161, 2013.

Kim, S., Lee, H., Woo, N. C., and Kim, J.: Soil moisture monitoring on a steep hillside, Hydrol. Process., 21, 2910-2922, 2007.

Legates, D. R., Mahmood, R., Levia, D. F., DeLiberty, T. L., Quiring, S. M., Houser, C., and Nelson, F. E.: Soil moisture: A central and unifying theme in physical geography, Prog. Phys. Geogr. 35, 65-86, 2011.

Lei, S.: Root distribution traits of apple trees in platform terrain, Journal Vocational College, 97-99, 2013 (in Chinese).

Liu, W., Zhang, X., Dang, T., Ouyang, Z., Li, Z., Wang, J., Wang, R., and Gao, C.: Soil water dynamics and deep soil recharge in a record wet year in the southern Loess Plateau of China, Agric. Water Manag., 97, 1133-1138, 2010.

Lu, Y., Fu, B., Chen, L., Liu, G., and Wei, W.: Nutrient transport associated with water erosion: progress and prospect, Prog. Phys. Geogr., 31, 607-620, 2007.

Lu, Y., Chen, L., and Fu, B.: Land-cover effects on red soil rehabilitation in China: a meta-analysis, Prog. Phys. Geogr., 32, 491502, 2008.

Mandal, U. K., Warrington, D. N., Bhardwaj, A. K., Bar-Tal, A., Kautsky, L., Minz, D., and Levy, G. J.: Evaluating impact of ir- 
rigation water quality on a calcareous clay soil using principal component analysis, Geoderma, 144, 189-197, 2008.

Martínez-Fernández, J. and Ceballos, A.: Temporal stability of soil moisture in a large-field experiment in Spain, Soil Sci. Soc. Am. J., 67, 1647-1656, 2003.

Montenegro, S. and Ragab, R.: Impact of possible climate and land use changes in the semi arid regions: a case study from North Eastern Brazil, J. Hydrol., 434-435, 55-68, 2012.

Qiu, Y., Fu, B., Wang, J., and Chen, L.: Soil moisture variation in relation to topography and land use in a hillslope catchment of the Loess Plateau, China, J. Hydrol., 240, 243-263, 2001.

Ruan, C. and Li, D.: Community characteristics of Hippophae rhamnoides forest and water and nutrient condition of the woodland in Loess hilly region, Ying Yong Sheng Tai Xue Bao, 13, 1061-1064, 2002 (In Chinese).

Savva, Y., Szlavecz, K., Carlson, D., Gupchup, J., Szalay, A., and Terzis, A.: Spatial patterns of soil moisture under forest and grass land cover in a suburban area, in Maryland, USA, Geoderma, 192, 202-210, 2013.

Shi, Y., Liu, Y., and Zhang, J.: Study on the root distribution of peach trees, Journal Fruit Science, 4, 232-235, 1989 (in Chinese).

Shi, Y., Wu, P., Zhao, X., Li, H., Wang, J., and Zhang, B.: Statistical analyses and controls of root-zone soil moisture in a large gully of the Loess Plateau, Environ. Earth Sci., 71, 4801-4809, 2014.

Starks, P. J., Heathman, G. C., Jackson, T. J., and Cosh, M. H.: Temporal stability of soil moisture profile, J. Hydrol., 324, 400-411, 2006.

Sun, F., Lü, Y., Fu, B., Ma, Z., and Yao, X.: Spatial explicit soil moisture analysis: pattern and its stability at small catchment scale in the loess hilly region of China, Hydrol. Process., 28, 4091-4109, 2014.

Vereecken, H., Kamai, T., Harter, T., Kasteel, R., Hopmans, J., and Vanderborght, J.: Explaining soil moisture variability as a function of mean soil moisture: a stochastic unsaturated flow perspective, Geophys. Res. Lett., 34, 315-324, 2007.

Vivoni, E. R., Rinehart, A. J., Méndez-Barroso, L. A., Aragón, C. A., Bisht, G., Cardenas, M. B., Engle, E., Forman, B. A., Frisbee, M. D., Gutiérrez-Jurado, H. A., Hong, S., Mahmood, T. H., Tai, K., and Wyckoff, R. L.: Vegetation controls on soil moisture distribution in the Valles Caldera, New Mexico, during the North American monsoon, Ecohydrology, 1, 225-238, 2008.

Wang, L., Wang, Q., Wei, S., Shao, M. A., and Li, Y.: Soil desiccation for Loess soils on natural and regrown areas, Forest Ecol. Manag., 255, 2467-2477, 2008a.

Wang, Y., Shao, M., and Zhang, X.: Soil moisture ecological environment of artificial vegetation on steep slope of loess region in North Shaanxi Province, China, Acta Ecol. Sin., 28, 885-894, 2008b (in Chinese).

Wang, Z., Liu, B., and Zhang, Y.: Soil moisture of different vegetation types on the Loess Plateau, J. Geogr. Sci., 19, 707-718, 2009.

Wang, Y., Shao, M., and Liu, Z.: Large-scale spatial variability of dried soil layers and related factors across the entire Loess Plateau of China, Geoderma, 159, 99-108, 2010a.

Wang, Y., Shao, M., and Liu, Z.: Large-scale spatial variability of dried soil layers and related factors across the entire Loess Plateau of China, Geoderma, 159, 99-108, 2010b.
Wang, Y., Shao, M., and Shao, H.: A preliminary investigation of the dynamic characteristics of dried soil layers on the Loess Plateau of China, J. Hydrol., 381, 9-17, 2010c.

Wang, Y., Shao, M., and Shao, H.: A preliminary investigation of the dynamic characteristics of dried soil layers on the Loess Plateau of China, J. Hydrol., 381, 9-17, 2010d.

Wang, X. C., Muhammad, T. N., Hao, M. D., and Li, J.: Sustainable recovery of soil desiccation in semi-humid region on the Loess Plateau, Agric. Water Manag., 98, 1262-1270, 2011 a.

Wang, Y., Shao, M., Zhu, Y., and Liu, Z.: Impacts of land use and plant characteristics on dried soil layers in different climatic regions on the Loess Plateau of China, Agr. Forest Meteorol., 151, 437-448, $2011 \mathrm{~b}$.

Wang, L., D’Odorico, P., Evans, J. P., Eldridge, D. J., McCabe, M. F., Caylor, K. K., and King, E. G.: Dryland ecohydrology and climate change: critical issues and technical advances, Hydrol. Earth Syst. Sci., 16, 2585-2603, doi:10.5194/hess-16-25852012, 2012a.

Wang, Y., Shao, M., Liu, Z., and Warrington, D. N.: Regional spatial pattern of deep soil water content and its influencing factors, Hydrol. Sci. J., 57, 265-281, 2012 b.

Wang, Y., Shao, M., Liu, Z., and Warrington, D. N.: Regional spatial pattern of deep soil water content and its influencing factors, Hydrol. Sci. J., 57, 265-281, 2012c.

Wang, Y., Shao, M., and Liu, Z.: Vertical distribution and influencing factors of soil water content within $21-\mathrm{m}$ profile on the Chinese Loess Plateau, Geoderma, 193-194, 300-310, 2013.

Wang, S., Fu, B., Piao, S., Lü, Y., Ciais, P., Feng, X., and Wang, Y.: Reduced sediment transport in the Yellow River due to anthropogenic changes, Nat. Geosci., 9, 38-41, 2015.

Wei, S., Ren, S., Yang, P., and Yan, M.: Soil moisture dynamic and root growth of alfalfa in Weichang region, Chinese Agricultural Science Bulletin, 5, 448-451, 2006 (in Chinese).

Western, A. W., Zhou, S., Grayson, R. B., McMahon, T. A., Blöschl, G., and Wilson, D. J.: Spatial correlation of soil moisture in small catchments and its relationship to dominant spatial hydrological processes, J. Hydrol., 286, 113-134, 2004.

Xu, X., Ma, K., Fu, B., Song, C., and Liu, W.: Relationships between vegetation and soil and topography in a dry warm river valley, SW China, Catena, 75, 138-145, 2008.

Yang, L., Wei, W., Chen, L., Jia, F., and Mo, B.: Spatial variations of shallow and deep soil moisture in the semi-arid Loess Plateau, China, Hydrol. Earth Syst. Sci., 16, 3199-3217, doi:10.5194/hess-16-3199-2012, 2012a.

Yang, L., Wei, W., Chen, L., and Mo, B.: Response of deep soil moisture to land use and afforestation in the semi-arid Loess Plateau, China, J. Hydrol., 475, 111-122, 2012b.

Yang, L., Wei, W., Chen, L., and Mo, B.: Response of deep soil moisture to land use and afforestation in the semi-arid Loess Plateau, China, J. Hydrol., 475, 111-122, 2012c.

Yang, L., Chen, L., Wei, W., Yu, Y., and Zhang, H.: Comparison of deep soil moisture in two re-vegetation watersheds in semi-arid regions, J. Hydrol., 513, 314-321, 2014a.

Yang, L., Wei, W., Chen, L., Chen, W., and Wang, J.: Response of temporal variation of soil moisture to vegetation restoration in semi-arid Loess Plateau, China, Catena, 115, 123-133, 2014 b.

Zhang, L. and $\mathrm{Xu}, \mathrm{X}$.: The distribution characteristics of Robinia pseudoacacia root in Yangou watershed in Yanan, Journal Northwest, Forestry College, 26, 9-14, 2011 (in Chinese). 
Zhao, J., Du, J., and Chen, B.: Dried earth layers of artificial forestland in the Loess Plateau of Shaanxi Province, J. Geogr. Sci., 17, 114-126, 2007.

Zhao, W. and Fang, X.: Landscape sustainability and landscape sustainability science, Acta Ecol. Sin., 34, 2453-2459, 2014 (in Chinese).

Zhao, W., Fu, B., and Chen, L.: A comparison between soil loss evaluation index and the C-factor of RUSLE: a case study in the Loess Plateau of China, hydrology and Earth Systerm, Science, 16, 2739-2748, 2012.

Zhao, W., Fu, B., and Qiu, Y.: An upscaling method for covermanagement factor and its application in the Loess Plateau of China, Int. J. Environ. Res. Public Health, 10, 4752-4766, 2013.
Zhu, Q. and Lin, H.: Influences of soil, terrain, and crop growth on soil moisture variation from transect to farm scales, Geoderma, 163, 45-54, 2011.

Zhu, H. D., Shi, Z. H., Fang, N. F., Wu, G. L., Guo, Z. L., and Zhang, Y.: Soil moisture response to environmental factors following precipitation events in a small catchment, Catena, 120, 73-80, 2014a.

Zhu, Q., Nie, X., Zhou, X., Liao, K., and Li, H.: Soil moisture response to rainfall at different topographic positions along a mixed land-use hillslope, Catena, 119, 61-70, 2014b. 